\title{
Process Parameters Effect on Weld Beads Geometry Deposited by Wire and Arc Additive Manufacturing (WAAM)
}

\author{
Supasit Manokruang ${ }^{(凶)}$, Frederic Vignat, Matthieu Museau, and Maxime Limousin \\ Univ. Grenoble Alpes, CNRS, Grenoble INP, G-SCOP, 38000 Grenoble, France \\ supasit.manokruangegrenoble-inp. fr
}

\begin{abstract}
Among Additive Manufacturing technologies, Wire and Arc Additive Manufacturing process is strongly dependent of deposition conditions such as welding parameters, substrate temperature, trajectory. In this research, geometry and temperature evolutions of single beads have been investigated according to process parameters modifications. For our experiment, a heating device have been used in order to control the substrate temperature from room temperature up to $400{ }^{\circ} \mathrm{C}$. Considering the Cold Metal Transfer technology, welding parameters, Wire Feed Speed (WFS) and Travel Speed (TS), have been modified while keeping a constant ratio $\lambda(W F S / T S)$. Results indicate that weld bead geometry, height $(h)$ and width $(w)$, is influenced by substrate temperature and welding parameters. It has been shown that substrate temperature, itself influenced by process parameters, tends to produce thicker and lower weld beads while it increases.
\end{abstract}

Keywords: Wire and Arc Additive Manufacturing · Additive Manufacturing . Cold Metal Transfer · Single weld bead · Thermal effect

\section{Introduction}

Additive Manufacturing (AM) technologies build up materials layer by layer, allowing complex shapes to be produced. Among various processes in AM, wire-base techniques show a lower energy requirement, about $85 \%$, than those based on powder $[1,2]$. For Wire and Arc Additive Manufacturing (WAAM) technology, several modes of energy distribution are available according to suppliers.

Cold Metal Transfer (CMT) is one of them and is very popular for arc welding. In effect, CMT process requires much less energy to work than tungsten inert gas (TIG) or plasma processes. Thanks to this lower energy, thin plates and low cladding of aluminum alloys have been possible. This specificity have been exploited in WAAM as, for example, several studies have shown its interest to be able to produce parts with maximize density [3-5]. Moreover, various study have shown that temperature and thermal accumulation in WAAM strongly influence parts geometry [6, 7]. As CMT technology uses a lower amount of energy compared to other techniques, it allows to minimize these deformation induced by heat accumulation. Unfortunately, when it comes to parts with complex 
shapes, it is difficult to predict nor control the temperature and its influence on the final geometry. This study places the first steps aiming at this understanding. It has been proposed to focus, at first, on weld bead as it constitutes the elementary brick of any volumic parts manufacturing.

This study investigates the interacting influences between the substrate temperature and the geometry evolution base on welding parameters of weld beads.

\section{Experimental Setup}

A YASKAWA MA1440 Robot and a Fronius TPS CMT 4000 Advanced welding station (Fronius, Pettenach, Austria) have been used in order to produce the different weld beads of $80 \mathrm{~mm}$ length. A $1.2 \mathrm{~mm}$ diameter aluminum wire, 5356 alloy, have been involved with a working distance of $15 \mathrm{~mm}$. An argon shielding gas was used with a flow rate of $13 \mathrm{~L} / \mathrm{min}$. Weld beads have been deposited on a ER5356 Al alloy substrate whose dimensions were $350 \mathrm{~mm} \times 350 \mathrm{~mm} \times 5 \mathrm{~mm}(w * l * h)$. Then, using the 875 CMT synergic law provided by Fronius, Wire Feed Speed (WFS) and Travel Speed (TS) have been modified while their ratio $\lambda=W F S / T S$ was kept constant at a value of 8.33 because at previous of the research experiment, these things use WFS $=5 \mathrm{~m} / \mathrm{min}, T S$ $=0.60 \mathrm{~m} / \mathrm{min}$ and ratio $=8.33$. Therefore, adding four different sets of parameter have thus been fixed as detailed in Table 1 .

Table 1. Process parameters for experiment

\begin{tabular}{l|l|l|l}
\hline Symbol & $W F S(\mathrm{~m} / \mathrm{min})$ & $T S(\mathrm{~m} / \mathrm{min})$ & Ratio \\
\hline A & 3 & 0.36 & \multirow{2}{*}{8.33} \\
\hline B & 4 & 0.48 & \\
\hline C & 5 & 0.60 & \\
\hline D & 6 & 0.72 & \\
\hline
\end{tabular}

In order to control precisely the substrate temperature $\left(T_{s u b}\right)$ of our constructions, a specific equipment has been designed. It is composed by 3 heating resistances $(6 \mathrm{~kW})$ allowing temperature regulation up to $500{ }^{\circ} \mathrm{C}$ thanks to an electrical controller. For the experiment needs, several substrate temperatures have been applied to all conditions A, $\mathrm{B}, \mathrm{C}$ and D. Starting at room temperature $\left(25^{\circ} \mathrm{C}\right)$, tests have been thus led at 100,200 , 300 and $400{ }^{\circ} \mathrm{C}$. As shown in Fig. 1. Smaller temperature increase have been revealed insufficient in our previous experiments to involve significant geometry evolutions. During production, evolutions of substrate temperature have been recorded thanks to four thermocouples (k type) placed along with the welding direction at a distance of $10 \mathrm{~mm}$ from weld beads and spread by $20 \mathrm{~mm}$. In the end, a 3D laser scanner (Artec Space Spider), with a resolution of $0.10 \mathrm{~mm}$, was used to acquire a precise numerical model of weld beads geometry from which height and width have been extracted. 


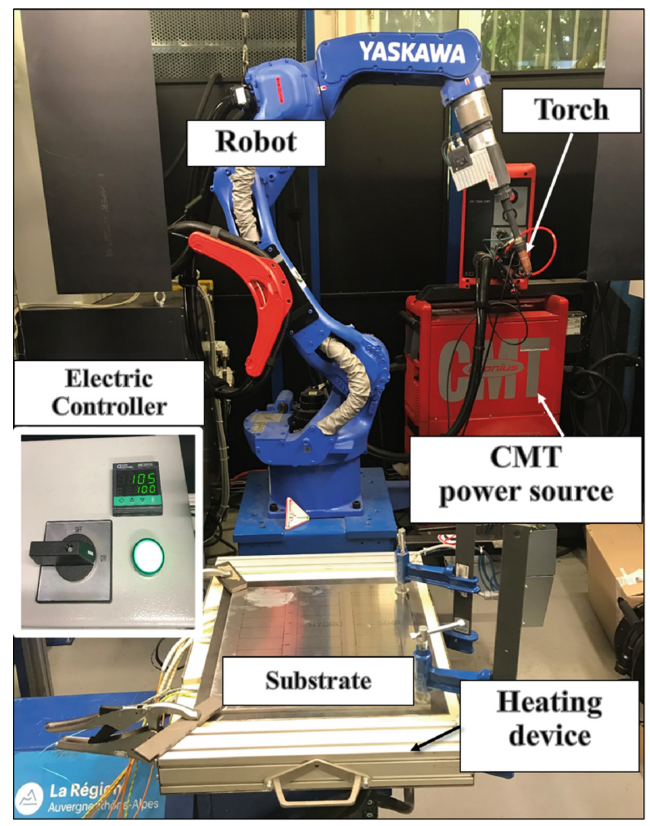

Machine \& device
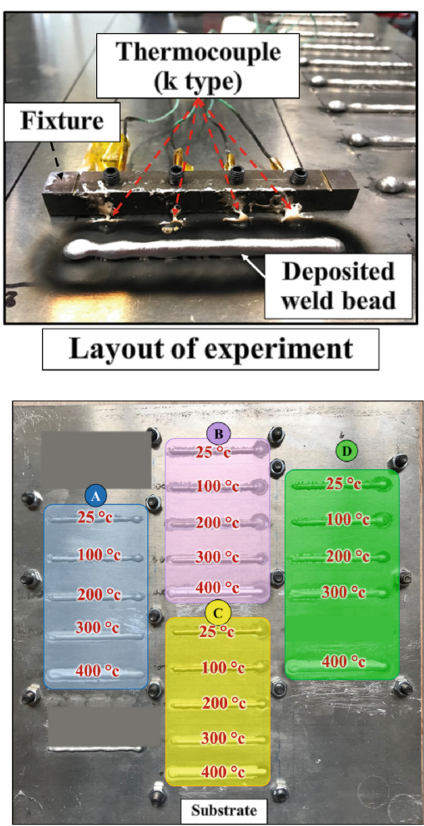

Result of experiment

Fig. 1. Installation device and experiment set up

\section{Results and Discussion}

\subsection{Temperature Evolution}

The recording system previously describe is able to give various information on substrate temperature during welding and its evolution. In this way, the maximum temperature peak $\left(T_{\max }\right)$ reached during the process can be easily obtained for each conditioned as well as the cooling time $\left(t_{\text {cool }}\right)$ needed to come back to the initial condition. All results have been compiled Table 2 .

Table 2. Temperature evolution according to process parameters

\begin{tabular}{|c|c|c|c|c|c|c|c|c|c|c|c|c|c|c|c|c|}
\hline \multirow[t]{2}{*}{$T_{\text {sub }}\left({ }^{\circ} \mathrm{C}\right)$} & \multicolumn{4}{|c|}{$T_{\max }\left({ }^{\circ} \mathrm{C}\right)$} & \multicolumn{4}{|c|}{$t_{\text {cool. }}(s)$} & \multicolumn{4}{|c|}{$\Delta T=T_{\max }-T_{\text {sub }}\left({ }^{\circ} \mathrm{C}\right)$} & \multicolumn{4}{|c|}{$\left(T_{\max }-T_{\text {sub }}\right) / T_{\text {sub }}(\%)$} \\
\hline & A & B & C & D & A & B & C & D & A & B & C & D & A & B & C & D \\
\hline 25 & 107 & 121 & 126 & 148 & 88 & 102 & 112 & 121 & 82 & 96 & 101 & 123 & 328 & 384 & 404 & 492 \\
\hline 100 & 178 & 183 & 186 & 207 & 73 & 91 & 93 & 114 & 78 & 83 & 86 & 107 & 78 & 83 & 86 & 107 \\
\hline 200 & 251 & 263 & 276 & 306 & 62 & 72 & 86 & 110 & 51 & 63 & 76 & 106 & 26 & 32 & 38 & 53 \\
\hline 300 & 344 & 355 & 370 & 373 & 45 & 53 & 62 & 69 & 44 & 45 & 70 & 73 & 15 & 18 & 23 & 24 \\
\hline 400 & 452 & 458 & 467 & 484 & 34 & 38 & 42 & 45 & 52 & 58 & 67 & 84 & 13 & 15 & 17 & 21 \\
\hline
\end{tabular}

From these data, several ascertainments can be pulled. It appears that $T_{\max }$ increase for higher WFS for each conditions, which seems logical as the deposited energy is driven 
by the amount of matter needed to be melted (WFS). As well, the rise of $T_{\text {sub }}$ induces obviously a rise in the recorded $T_{\max }$ but in different proportions between a weld at room temperature and another one done at $100,200,300$ and $400{ }^{\circ} \mathrm{C}$. In this sense, even if $T_{\max }$ is increasing with WFS, conversely, $t_{c o o l}$ is decreasing and the temperature is stabilizing rather faster. This phenomenon can be explained by the fact that the difference in temperature $\Delta T\left(T_{\max }-T_{\text {sub }}\right)$ is smaller.

\section{Geometry Evolution}

Using the numerical model provided by the 3D scanner, beads dimensions have been extracted. At first, the height has been measured as the average maximum highness. For this, the full bead length have been considered without both first and final $10 \mathrm{~mm}$ in order to not be influenced by arc ignition and extinction. From here, the width is measured as the average largeness extracted from a cross-section placed at mid-height and parallel to the substrate. Results are shown in Fig. 2 according to welding conditions and substrate temperature.

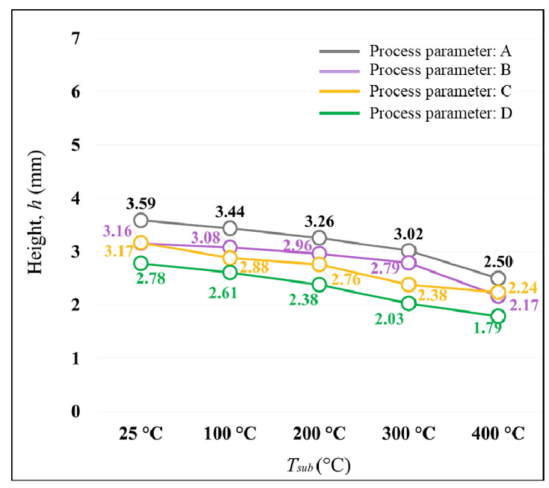

(a)

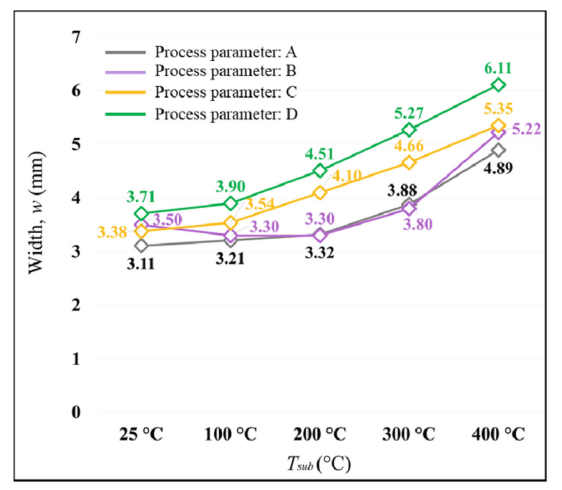

(b)

Fig. 2. Evolution of weld beads dimensions: (a) Height, h and (b) Width, w.

As we initially fixed a constant $\lambda$ ratio, height and width are strongly linked and their product remain constant. Thus, while height is increasing or decreasing, width decreases or increases in the opposite way.

Considering this, mainly two parameters lead geometry evolutions of weld beads as can be observed in Fig. 2. In effect, as $W F S$ and $T_{s u b}$ rise, height decreases and width increases. This flattening of weld beads can be explained by the fact that these two factors are responsible for a general increase in temperature and leads to improve the wetting angle and fluidity of aluminum [8].

These geometrical evolutions can be important as for example, considering a constant $W F S$, there is a difference of $1 \mathrm{~mm}$ in height and almost $2 \mathrm{~mm}$ in width between a weld bead done at room temperature and another one welded on a $400{ }^{\circ} \mathrm{C}$ hot substrate. 
Equally, for a constant $T_{s u b}$, a $W F S$ increase by a factor of 2 is responsible for a dimension variation about $1 \mathrm{~mm}$ in height and width.

These evolutions, bring back to the dimension of a weld bead, could be disastrous for parts construction if not taken into account.

\section{Conclusion}

This experiment has investigated some process parameters of Wire and Arc Additive Manufacturing process and their influences on geometry evolution of weld beads. An experiment was performed in order to track the evolution of temperature and weld beads dimensions. It has revealed that, for a constant amount of deposited material, the main parameters driving geometrical evolutions are WFS and $T_{s u b}$. Whether by the fact that they directly control the input energy or by their nature, they both contribute to the general increase in temperature. In turn, this temperature rise leads to a better wetting angle and decreases the aluminum viscosity. In the end, weld beads tend to be lower and larger.

Those geometrical evolutions, potentially being driven, have to be imperatively considered as the temperature during the WAAM process is difficult to manage, especially on parts with complex shapes. Thus, a small difference on a weld bead can lead to important derives with a stack of dozens and dozens of layers.

The future work will study a single wall bead and kept constants temperature respective of deposition a new layer. It will provide important information for process planning WAAM.

\section{References}

1. Ding, D., Pan, Z., Cuiuri, D., Li, H.: A multi-bead overlapping model for robotic wire and arc additive manufacturing (WAAM). Robot. Comput. Integr. Manuf. 31, 101-110 (2015)

2. Jackson, M.A., Van Asten, A., Morrow, J.D., Min, S., Pfefferkorn, F.E.: A comparison of energy consumption in wire-based and powder-based additive-subtractive manufacturing. Procedia Manuf. 5, 989-1005 (2016)

3. Xu, X., Ding, J., Ganguly, S., Diao, C., Williams, S.: Preliminary investigation of building strategies of maraging steel bulk material using wire + arc additive manufacture. J. Mater. Eng. Perform. 28(2), 594-600 (2018)

4. Cong, B., Ding, J., Williams, S.: Effect of arc mode in cold metal transfer process on porosity of additively manufactured Al-6.3\%Cu alloy. Int. J. Adv. Manuf. Technol. 76(9-12), 1593-1606 (2014)

5. Sergio, R., Colegrove, P.A., Martina, F., Williams, S.W.: Analytical process model for wire + arc additive manufacturing. J. Addit. Manuf. 21, 651-657 (2018)

6. Wu, B., et al.: Effects of heat accumulation on the arc characteristics and metal transfer behavior in Wire Arc Additive Manufacturing of Ti6Al4V. J. Mater. Process. Technol. 250, 304-312 (2017)

7. Wu, B., Pan, Z., Duin, S.V., Li, H.: Thermal behavior in wire arc additive manufacturing: characteristics, effects and control. Trans. Intell. Weld. Manuf. 2, 3-18 (2018)

8. Rodrigues, T.A., Duarte, V., Santos, T.G., Oliverira, J.P.: Current status and perspectives on wire and arc additive manufacturing (WAAM). J. Mater. 12, 1121-1162 (2019) 
Open Access This chapter is licensed under the terms of the Creative Commons Attribution 4.0 International License (http://creativecommons.org/licenses/by/4.0/), which permits use, sharing, adaptation, distribution and reproduction in any medium or format, as long as you give appropriate credit to the original author(s) and the source, provide a link to the Creative Commons license and indicate if changes were made.

The images or other third party material in this chapter are included in the chapter's Creative Commons license, unless indicated otherwise in a credit line to the material. If material is not included in the chapter's Creative Commons license and your intended use is not permitted by statutory regulation or exceeds the permitted use, you will need to obtain permission directly from the copyright holder.

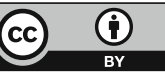

